\title{
Left Ventricular Structure, Geometry and Systolic Function among Hypertensive Black Patients with Reduced Kidney Function
}

\author{
B. C. Mpembe1, F. B. Lepira2 ${ }^{*}$, F. I. Mbutiwi², J. R. Makulo², E. V. Kintoki'1, M. P. Bayauli³, \\ J. R. M'Buyamba-Kabangu 1 \\ ${ }^{1}$ Division of Cardiology and Hypertension, Kinshasa School of Medicine, University of Kinshasa, Kinshasa, \\ Democratic Republic of the Congo \\ ${ }^{2}$ Division of Nephrology, Kinshasa School of Medicine, University of Kinshasa, Kinshasa, Democratic Republic of \\ the Congo \\ ${ }^{3}$ Division of Endocrinology and Metabolic Diseases, Kinshasa School of Medicine, University of Kinshasa, \\ Kinshasa, Democratic Republic of the Congo \\ Email: ${ }^{*}$ lepslepira@yahoo.fr
}

Received 18 May 2015; accepted 17 October 2015; published 20 October 2015

Copyright (C) 2015 by authors and Scientific Research Publishing Inc.

This work is licensed under the Creative Commons Attribution International License (CC BY). http://creativecommons.org/licenses/by/4.0/

(c) (i) Open Access

\begin{abstract}
Objective: To assess the LV mass, geometry and systolic function in hypertensive patients with reduced kidney function. Methods: According to ASE guidelines, we estimated LV ventricular mass, geometry and systolic function in 155 consecutive hypertensive patients [51\% women, mean age $51 \pm 12$ years, median duration of hypertension 7 years] with reduced kidney function [eGFR $<60$ $\mathrm{ml} / \mathrm{min} / 1.73 \mathrm{~m}^{2}$ or dipstick proteinuria $\geq 1+$ ). $\mathrm{LVH}$ was defined as LVMI $>125 \mathrm{~g} / \mathrm{m}^{2}$ in men, $>110$ $\mathrm{g} / \mathrm{m}^{2}$ in non obese women or $>51 \mathrm{~g} / \mathrm{m}^{2.7}$ for obese men or women. Where appropriate, we used Student $t$, Mann Whitney, one way ANOVA or Chi square tests. A P value of 0.05 or less was considered significant. Results: Seventy four patients in the series $(48 \%)$ had reduced kidney function (eGFR $30 \pm 15 \mathrm{ml} / \mathrm{min} / 1.73 \mathrm{~m}^{2}$ ). Compared to patients with relatively normal kidney function, non obese and obese patients with reduced kidney function had significantly greater LVM [271 (198 348) vs $276(175-284) \mathrm{g} / \mathrm{m}^{2}, \mathrm{p}=0.008$ ) for non obese; LVM $72(47-88)$ vs $54(44-73) \mathrm{g} / \mathrm{m}^{2.7}, \mathrm{p}=$ 0.007 for obese] and lower EF $(60 \pm 14$ vs $68 \pm 13 \%, p<0.001)$ was significantly lower. LVH of mainly concentric geometric pattern was present in 68 patients with reduced kidney function (92\%). Conclusion: In the present case series, reduced kidney function was associated with increased LVM, concentric geometric pattern and impaired systolic function.
\end{abstract}

\section{Keywords}

Echocardiographic-LVH, Reduced Kidney Function, Hypertension, Black Africans

\footnotetext{
${ }^{*}$ Corresponding author.

How to cite this paper: Mpembe, B.C., Lepira, F.B., Mbutiwi, F.I., Makulo, J.R., Kintoki, E.V., Bayauli, M.P. and M'BuyambaKabangu, J.R. (2015) Left Ventricular Structure, Geometry and Systolic Function among Hypertensive Black Patients with Reduced Kidney Function. World Journal of Cardiovascular Diseases, 5, 287-295.

http://dx.doi.org/10.4236/wjcd.2015.510032
} 


\section{Introduction}

Left ventricular hypertrophy (LVH) and abnormal LV geometry are important markers of cardiovascular risk in hypertensive as well as chronic kidney disease (CKD) patients [1] [2]. They are associated with increased cardiovascular morbidity due to progressive ischaemic compromise, systolic and/or diastolic dysfunction, arrhythmias and sudden cardiac death [3]. LVH in hypertension is also associated with increased prothrombotic state, microalbuminuria, higher systolic hypertension, increased body mass index, fasting serum lipids and blood sugar levels [4]. Adaptation of the LV to increasing wall tension, pressure and volume changes in hypertension may result in four LV geometric patterns (normal, concentric remodeling, eccentric hypertrophy and concentric hypertrophy) based on relative wall thickness and LV mass [1] [2]. These patterns bear potential significant impact on systolic and/or diastolic function of the left ventricle [1] [2] and hence, could help to identify subjects at high risk for cardiovascular disease (CVD) who can benefit from preventive measures [5].

In the Democratic Republic of the Congo (DRC), the prevalence of hypertension and CKD has been estimated to be of $30 \%$ and $12 \%$, respectively [6]-[8]. LVH and CKD are target organ damage (TOD) commonly seen in hypertensive patients [9] [10]. While LVH and its geometric patterns have already been described in type 2 diabetic patients with CKD [11], the exploration has not yet been done among hypertensive patients with CKD. Therefore, the aim of the present work was to study the pattern and clinical correlates of LVH and geometry among hypertensive patients with reduced kidney function (RKF).

\section{Methods}

Treated and naïve consecutive hypertensive patients $(n=155 ; 51 \%$ females $)$ referred for echocardiography to the Division of Cardiology of the University of Kinshasa Hospital between January 6, 2012 and January 10, 2013 were enrolled in the present study. We collected information on age, gender, duration of hypertension, lifestyle habits (alcohol intake, smoking, physical activity), history of diabetes and, current medication for chronic diseases and measured body weight, height, waist circumference and seated blood pressure. Blood pressure was recorded using an electronic device (Zydus, Andon Health Co, Tianjin, China) with appropriate cuff secured on the left arm after at least five minutes at rest. Hypertension was systolic/diastolic blood pressure $\geq$ 140/90 mmHg on two separate hospital visits at one week interval or use of antihypertensive therapy [12]. Hypertension duration was the time elapsed from diagnosis to the present procedure. We calculated body mass index (BMI) as weight (in $\mathrm{Kg}$ ) divided by the square of height (in $\mathrm{m}$ ) and defined overweight and obesity as BMI $\geq 25$ and $\geq 30 \mathrm{Kg} / \mathrm{m}^{2}$, respectively [13]. We obtained measurements of blood hemoglobin, hematocrit, fasting plasma glucose (FPG), lipids and serum creatinine and a dipistick qualitative proteinuria. Anemia was blood hemoglobin $<12 \mathrm{~g} / \mathrm{dl}$ in men or $<11 \mathrm{~g} / \mathrm{dl}$ in women [14]. Diabetes was fasting plasma glucose $\geq 126$ $\mathrm{mg} / \mathrm{dl}$ or use of antidiabetic drugs [15]. We estimated the glomerular filtration rate (GFR, $\mathrm{ml} / \mathrm{min} / 1.73 \mathrm{~m}^{2}$ ) using the abbreviated Modification of Diet in Renal Disease equation (MDRD) [16]. Reduced kidney function (RKF) was defined as GFR $<60 \mathrm{ml} / \mathrm{min} / 1.73$ or dipstick proteinuria $\geq 1+$ and was stratified according to Kidney Disease Outcome Quality Initiative (KDOQI) [17]. We used NCEP-ATP III criteria to define metabolic syndrome (MetS) [18].

With the patient in the left lateral decubitus position, we performed a transthoracic two-dimensional guided M-mode echocardiography in the parasternal view using a 3.5-Hz transducer equipped cardiac ultrasound machine (Acuson Corporation, Mountain View, California, USA). LV measurements were obtained at end-diastole and end-systole following the recommendations of the American Society of Echocardiography (ASE) [19]. LV internal diameters in systole (LVIDs) and in diastole (LVIDd), interventricular septal thickness (IVSTd) and posterior wall thickness (PWTd) were obtained only in diastole. These measurements were the average of three cardiac cycles [20]. LV mass (LVM) was calculated using the modified Devereux formula: LV mass (g) $=0.8$ [1.04 (IVSTd + PWTd + LVIDd) ${ }^{3}-$ LVIDd $\left.\left.^{3}\right]+0.6\right]$ [21] and was indexed (LVMI) to body surface area and by the allometric power of height for lean and obese patients, respectively [22]. LVH was considered present when LVMI was $>125 \mathrm{~g} / \mathrm{m}^{2}$ for men and $>110 \mathrm{~g} / \mathrm{m}^{2}$ for women or $>51 \mathrm{~g} / \mathrm{m}^{2.7}$ for both sexes [12] [23]. The relative wall thickness (RWT) was double the ratio of PWTd to LVIDd; a RWT > 0.42 was considered as high [23]. Four LV geometric patterns were derived from the combination of LVMI and RWT as follows: normal geometry (both LVMI and RWT normal); concentric remodeling (RWT increased, LVMI normal); eccentric hypertrophy (LVMI increased, RWT normal) and concentric hypertrophy (both RWT and LVMI increased) [24]. Enddiastolic and end-systolic LV volumes by Teichholz method were used to compute LV ejection (EF) and short- 
ening (SF) fractions ${ }^{1}$; the LV systolic dysfunction was $\mathrm{EF}<50 \%$ or $\mathrm{SF}<28 \%$ [1].

\section{Statistical Analyses}

Data are presented as means \pm SD for normally distributed variables, median and interquartile range (IQR) for skewed variables and frequencies and percentages for categorical variables. Student $t$ test and Mann Whitney Wilcoxon test were used to compare continuous variables in patients with and without RKF and one-way analysis of variance (ANOVA) in patients at different stages of RKF. Comparison of categorical variables was done using Chi square test. $\mathrm{P}$ value $<0.05$ defined the level of statistical significance.

\section{Results}

Main clinical and biological characteristics of the study population and difference according to renal function status are shown in Table 1 and Table 2. RKF was observed in 74 hypertensive patients (53\% females, mean age $59 \pm 12$ years), 34 (46\%), 27 (36\%) and $13(18 \%)$ of whom being on stage 3, 4 and 5, respectively. Compared to patients with relatively normal kidney function (NKF), those with RKF had a longer duration of hypertension [8 (4 - 12) vs $6(1-13)$ years; $\mathrm{p}=0.004)$, a greater BMI $\left(27 \mathrm{vs} 25 \mathrm{Kg} / \mathrm{m}^{2} ; \mathrm{p}=0.04\right)$ and WC $(95 \pm 14 \mathrm{vs}$ $95 \pm 14 \mathrm{~cm} ; \mathrm{p}=0.03$ ). The proportions of RKF patients receiving one, two or more antihypertensive drugs, amounted to 45 (61\%), 20 (27\%) and 4 (5\%) patients, respectively. Uncontrolled hypertension predominated among patients with RKF (77 vs 62\%; p = 0.04) who also had higher FPG [101 (86 - 126) mg/dl], uric acid (7.4 \pm 2.8 vs $5.5 \pm 2.2 \mathrm{mg} / \mathrm{dl} ; \mathrm{p}<0.001)$ but lower hemoglobin ( $11 \pm 2$ vs $13 \pm 2 \mathrm{~g} / \mathrm{dl} ; \mathrm{p}<0.001$ ) or hematocrit (35\% vs $40 \%$; $\mathrm{p}<0.001)$. Patients with RKF had a higher proportion of subjects with global obesity ( $30 \%$ vs $10 \%$; $\mathrm{p}=$ 0.002 ), central obesity ( $55 \%$ vs $39 \%$; $\mathrm{p}=0.04$ ), diabetes ( $38 \%$ vs $6 \%$; $\mathrm{p}<0.001)$, hyperuricemia ( $54 \%$ vs $21 \%$;

Table 1. Clinical characteristics of the study population as a whole and according to kidney function status.

\begin{tabular}{|c|c|c|c|c|}
\hline Variables & $\begin{array}{c}\text { All group } \\
\mathrm{n}=155\end{array}$ & $\begin{array}{c}\text { NKF } \\
\mathrm{n}=81\end{array}$ & $\begin{array}{c}\text { RKF } \\
\mathrm{n}=74\end{array}$ & $\mathrm{p}$ \\
\hline Gender, \% M & 49 & 51 & 47 & 0.681 \\
\hline $\mathrm{F}$ & 51 & 49 & 53 & \\
\hline Age, years & $58 \pm 12$ & $58 \pm 12$ & $59 \pm 12$ & 0.732 \\
\hline DHT, years & $7(2-13)$ & $6(1-13)$ & $8(4-12)$ & 0.040 \\
\hline Smoking, \% & 20 & 22 & 18 & 0.470 \\
\hline Physical activity, \% & 60 & 66 & 54 & $<0.001$ \\
\hline BMI, $\mathrm{Kg} / \mathrm{m}^{2}$ & $26 \pm 5$ & $25 \pm 4$ & $27 \pm 5$ & 0.047 \\
\hline Obesity, \% & 19 & 10 & 30 & 0.002 \\
\hline WC, cm & $93 \pm 14$ & $90 \pm 13$ & $95 \pm 14$ & 0.031 \\
\hline Central obesity, \% & 47 & 39 & 55 & 0.048 \\
\hline SBP, mm Hg & $158 \pm 24$ & $157 \pm 24$ & $159 \pm 25$ & 0.510 \\
\hline DBP, mm Hg & $93 \pm 17$ & $94 \pm 15$ & $93 \pm 18$ & 0.890 \\
\hline PP, mm Hg & $65 \pm 20$ & $63 \pm 18$ & $68 \pm 22$ & 0.180 \\
\hline Heart rate, bpm & $84 \pm 14$ & $83 \pm 15$ & $84 \pm 14$ & 0.600 \\
\hline AntiHT regimen, \% & & & & 0.530 \\
\hline - Monotherapy & 64 & 64 & 63 & \\
\hline - Bitherapy & 28 & 28 & 27 & \\
\hline$-\geq 3$ drugs & 3 & 1 & 5 & \\
\hline Uncontrolled BP, \% & 69 & 62 & 77 & 0.040 \\
\hline
\end{tabular}

Data are expressed as mean \pm standard deviation, median (range) or relative frequency in percent. Abbreviations: RKF \& NKF, reduced and relatively normal kidney function M, male F, female DHT, duration of hypertension BMI, body mass index WC, waist circumference SBP, systolic blood pressure DBP, diastolic blood pressure PP, pulse pressure HR, heart rate AntiHT, antihypertensive. 
Table 2. Biological characteristics of the study population as a whole and according to kidney function status.

\begin{tabular}{|c|c|c|c|c|}
\hline Variables & $\begin{array}{l}\text { All group } \\
\mathrm{n}=155\end{array}$ & $\begin{array}{c}\text { NKF } \\
\mathrm{n}=81\end{array}$ & $\begin{array}{c}\text { RKF } \\
\mathrm{n}=74\end{array}$ & $\mathrm{p}$ \\
\hline $\mathrm{Hb}, \mathrm{g} / \mathrm{dl}$ & $12 \pm 2$ & $13 \pm 2$ & $11 \pm 2$ & $<0.001$ \\
\hline $\mathrm{Ht}, \%$ & $37 \pm 7$ & $40 \pm 5$ & $35 \pm 7$ & $<0.001$ \\
\hline Anemia, \% & 39 & 24 & 54 & $<0.001$ \\
\hline FPG, mg/dl & $92(82$ - 109) & $90(79-97)$ & $101(86$ - 128) & $<0.001$ \\
\hline Diabetes, \% & 21 & 6 & 38 & $<0.001$ \\
\hline Uric acid, mg/dl & $6.4 \pm 2.6$ & $5.5 \pm 2.2$ & $7.4 \pm 2.8$ & $<0.001$ \\
\hline Hyperuricemia, \% & 39 & 21 & 54 & $<0.001$ \\
\hline $\mathrm{TC}, \mathrm{mg} / \mathrm{dl}$ & $111(85-151)$ & $116(88-171)$ & $100(84-137)$ & 0.660 \\
\hline LDL-c, mg/dl & $198 \pm 58$ & $198 \pm 58$ & $198 \pm 58$ & 0.090 \\
\hline HDL-c, mg/dl & $44(35-52)$ & $44(36-53)$ & $40(31$ - 49) & 0.160 \\
\hline TG, mm Hg & $96(76-125)$ & $90(76-110)$ & $98(77$ - 128) & 0.310 \\
\hline Dyslipidemia, \% & 79 & 80 & 77 & 0.630 \\
\hline MetS, \% & 46 & 31 & 62 & $<0.001$ \\
\hline Creatinine, mg/dl & $1.4(1-3)$ & $1.0(0.9-1)$ & $2.8(2-4)$ & $<0.001$ \\
\hline MDRD-GFR, ml/min/1.73 m² & $61 \pm 37$ & $89 \pm 26$ & $30 \pm 15$ & $<0.001$ \\
\hline Dipstick-proteinuria, \% & 17 & 6 & 28 & $<0.001$ \\
\hline \multicolumn{5}{|l|}{ RKF, stages, \% } \\
\hline 3 & - & - & 46 & \\
\hline 4 & - & - & 36 & \\
\hline 5 & - & - & 18 & \\
\hline
\end{tabular}

Data are expressed as mean \pm standard deviation, median (range) or relative frequency in percent. Abbreviations: RKF \& NKF, reduced and relatively normal kidney function $\mathrm{Hb}$, hemoglobin Ht, hematocrit FBG, fasting plasma glucose TC, total cholesterol LDL-c, low-density lipoprotein cholesterol HDL-c, high-density lipoprotein cholesterol TG, triglycerides MetS, metabolic syndrome MDRD, modification of diet in renal disease GFR, glomerular filtration rate.

$\mathrm{p}<0.001$ ), proteinuria (28\% vs 6\%; $\mathrm{p}<0.001$ ), MetS (62\% vs 31\%; $\mathrm{p}<0.001$ ), anemia ( $54 \%$ vs $24 \%$; $\mathrm{p}<0.001$ ) and lower proportion of physically active individuals ( $66 \%$ vs $54 \%$; $\mathrm{p}<0.001$ ).

Echocardiographic LV dimensions are shown in Table 3 for the whole study population and according to renal function status. In comparison to those with relatively NKF, RKF patients had greater LVIDd (51 \pm 8 vs $47 \pm 7 \mathrm{~mm} ; \mathrm{p}<0.001)$, LVIDs (34 \pm 9 vs $29 \pm 7 \mathrm{~mm} ; \mathrm{p}<0.001)$, IVSTd [12 (10 - 13) vs $11(0.9-12) \mathrm{mm} ; \mathrm{p}=$ 0.003], PWTd [12 (10 - 13) vs 10 (0.8 - 12) mm; p < 0.001], LVMI (BSA) [276 (198 - 348) vs 216 (175 - 284); $\mathrm{p}=0.008]$ and LVMI (height $\left.{ }^{2.7}\right)$ [72 (47 - 88) vs $\left.24(44-73) \mathrm{g} / \mathrm{m}^{2.7} ; \mathrm{p}=0.007\right]$. LVH was present in $68 \mathrm{RKF}$ patients (92\%) of whom $50 \%$ and $42 \%$ had concentric and eccentric geometric patterns, respectively. Concentric pattern of $\mathrm{LVH}$ was present in $47 \%, 63 \%$ and $31 \%$ of patients with RKF stage 3, 4 and 5, respectively; these proportions were $41 \%, 33 \%$ and $61 \%$ for the eccentric pattern; however, the differences observed between RKF stages were not statistically significant.

LV systolic dysfunction was observed in 16 (22\%), 21 (28\%) and 22 (30\%) of patients with RKF using EF, SF criteria and the combination of the two criteria, respectively (Table 3). Compared to patients with relatively NKF, those with RKF had a significantly higher proportion of LV systolic dysfunction using either criterion (EF: $22 \%$ vs $10 \%$; $p=0.04$; SF: $28 \%$ vs $12 \%$; $p=0.01$ ) or their combination $(\mathrm{EF}+\mathrm{SF}$ : $30 \%$ vs $12 \%$; $\mathrm{p}=0.008)$. LV systolic dysfunction using EF criterion was present in $23 \%, 22 \%$ and $15 \%$ of patients with RKF stage 3, 4 and 5, respectively. These proportions were $26 \%, 37 \%$ and $15 \%$ using SF criterion and $29 \%, 37 \%$ and $15 \%$ using the 
Table 3. Echocardiographic left ventricular dimensions, mass and systolic function of the study population as a whole and according to kidney function status.

\begin{tabular}{|c|c|c|c|c|}
\hline Variables & $\begin{array}{c}\text { All } \\
\mathrm{n}=155\end{array}$ & $\begin{array}{c}\text { NKF } \\
\mathrm{n}=81\end{array}$ & $\begin{array}{c}\text { RKF } \\
\mathrm{n}=74\end{array}$ & $\mathrm{p}$ \\
\hline \multicolumn{5}{|l|}{ LV dimensions } \\
\hline LVIDd, mm & $49 \pm 8$ & $47 \pm 7$ & $51 \pm 8$ & $<0.001$ \\
\hline LVIDs, mm & $31 \pm 9$ & $29 \pm 7$ & $34 \pm 9$ & $<0.001$ \\
\hline IVSTd, mm & $12(7-13)$ & $11(0.9-12)$ & $12(10-13)$ & 0.003 \\
\hline PWTd, mm & $11(0.9-13)$ & $10(0.8-12)$ & $12(10-13)$ & $<0.001$ \\
\hline LVMI, $g / \mathrm{m}^{2}$ & $239(178$ - 325) & $216(175-284)$ & $276(198-348)$ & 0.008 \\
\hline LVMI, g/m $\mathrm{m}^{2.7}$ & $63(45-80)$ & $54(44-73)$ & $72(47-88)$ & 0.007 \\
\hline LVH, \% & 91 & 92 & 92 & 0.280 \\
\hline \multicolumn{5}{|l|}{ LV geometry } \\
\hline Normal, \% & 6 & 7 & 4 & 0.370 \\
\hline Concentric remodeling, \% & 3 & 1 & 4 & 0.350 \\
\hline Eccentric hypertrophy, \% & 46 & 51 & 42 & 0.250 \\
\hline Concentric hypertrophy, \% & 45 & 41 & 50 & 0.280 \\
\hline \multicolumn{5}{|l|}{ LV systolic function } \\
\hline $\mathrm{EF}, \%$ & $64 \pm 14$ & $68 \pm 13$ & $60 \pm 14$ & $<0.001$ \\
\hline SF, \% & $36 \pm 11$ & $39 \pm 10$ & $34 \pm 11$ & 0.005 \\
\hline $\mathrm{EF}<50 \%, \%$ & 15 & 10 & 22 & 0.043 \\
\hline $\mathrm{SF}<28 \%, \%$ & 20 & 12 & 28 & 0.013 \\
\hline $\mathrm{EF}<50 \%+<28 \%, \%$ & 21 & 12 & 30 & 0.008 \\
\hline
\end{tabular}

Data are expressed as mean \pm standard deviation, median (range) or relative frequency in percent. Abbreviations: RKF \& NKF, reduced and relatively normal kidney function LVIDD, left ventricular internal diameter diastolic LVIDS, left ventricular internal diameter systolic, IVSD, interventricular septum diastolic PWT, posterior wall thickness diastolic LVMI, left ventricular mass index LVH, left ventricular hypertrophy EF, ejection fraction SF, shortening fraction.

combination of both criteria. However, the differences observed between RKF stages were not statistically significant.

\section{Discussion}

The main findings of the present study are as follows: first, LV dimensions and mass were higher in patients with RKF 92\% of whom showing the concentric geometric pattern of LVH. Second, LV systolic dysfunction was more frequent in patients with RKF.

The observation of greater LV dimensions and mass in patients with RKF agrees with previous studies reporting an increase in LVM among hypertensive patients with progressive decline in GFR [24] [25]. Nardi et al. [24] found that values of LVM progressively increased from CKD stage 2 to 5 . An inverse association between LVM and GFR was also reported by Redon et al. [25]

In Sub-Saharan Africa [20] [26]-[28], the prevalence of LVH in hypertensive patients with RKF has generally been reported to be elevated. The frequency of LVH in our study is quite similar to the $95.5 \%$ reported by Ulasi et al. [26] among 98 Nigerian hypertensive patients with RKF stage 4 and 5. It is however somewhat higher than the $74.2 \%$ [27], 62.7\% [20], 38.9\% [28], 51.3\% [29] and 34\% [30] that were observed in other studies of Nigerian patients. Niakara et al. [31] in Burkina Faso reported a frequency of 53.3\% clearly lower than ours. The reason for such a disparity is not certain; it could rely on the inherent characteristics of the populations that were studied or in differences in applied methodology. Indeed, RKF was associated in the present study with a high 
proportion of subjects with MetS [1] [2] [4] [32], anemia [33] and uncontrolled hypertension [34], all of which are well-known risk factors for LVH. Although hypertension, altered fluid and electrolyte balance, and anemia have been identified as major determinants of LVH in CKD, non hemodynamic factors such as inappropriate activation of the renin angiotensin aldosterone system, oxidative stress, inflammation, collagen and muscle cell growth factors may still play a relevant role [35]

In agreement with several reports from Nigeria [20] [36] and Burkina Faso [31], concentric LVH was the commonest geometric pattern found in the present case series. However; probably because of inclusion of patients with exclusively RKF stage 4 and 5, Ulasi et al. [26] found a higher prevalence of eccentric than concentric LVH. It is well-known that concentric LVH prevails in earlier stages of CKD due to pressure overload whereas eccentric geometric pattern occurs in advanced stages of CKD as a result of volume overload [24]. To this respect, Nardi et al. [24] stressed out that at CKD stage 4 to 5, the increase in LV mass relies more upon the increase in posterior wall thickness than in LV diameter in diastole.

By contrast to our finding, Adeseye et al. [37] observed a higher frequency of normal geometry and concentric remodeling in treated Nigerian hypertensive patients. Apart from the stage of CKD, this disparity could also be explained by the use of antihypertensive drugs such as the renin angiotensin system inhibitors and/or calcium channel blockers known to induce the regression of LVH [38]. In addition to hemodynamic factors, proinflammatory cytokines mainly c-reactive protein (CRP) and interleukin 6 (IL-6) may promote cardiac remodeling by stimulating sarcomeric protein synthesis, enhancing fetal gene expression, altering extracellular matrix degradation and triggering apoptosis [39].

At variance with the results showing a significant increase in LV dimensions, wall thickness, mass and hypertrophy from CKD stage 3 to 5 [40] [41], the decline of GFR in our study did not affect the frequency of LVH or its geometric patterns. The frequency of LVH was reported to pass from $64 \%$ at earlier CKD stages to $96 \%$ at advanced stage in the paper by Sambi et al. [40] and from 48\% at CKD stage 3\% to 75\% at stage 4 - 5 in that by Park et al. [41]. With reference to LVH geometric patterns, Sambi et al. [40] found an increase in the frequency of concentric LVH from $40 \%$ at earlier CKD stages to $68 \%$ at advanced CKD stages. In accordance with our data, Nardi et al. [24] found no increase in the frequency of concentric or eccentric LVH geometric patterns with the decline of GFR. However, when using the mixed pattern (concentric + eccentric LVH), they reported significant differences in the frequency of geometric patterns. The increased frequency of LVH and its concentric pattern reported in CKD might be related to high plasma aldosterone levels that are known to promote a LV concentric geometry and increase LVM [42].

The frequent LV systolic dysfunction in patients with RKF agrees with the observation by Arodiwe et al. [43] among pre-dialysis Nigerian patients. An inverse association between CKD and LV systolic function has also been reported by Grabysa et al. [44] who noted a decrease in the ejection fraction as well as the E/A ratio with progressive decline in GFR. Left ventricular systolic dysfunction is thought to result from cardiac remodeling triggered by the interaction of traditional and CKD specific hemodynamic and non hemodynamic risk factors [35] [39].

Some limitations of the present study need to be underscored. Measurements being observer-dependent, one limitation of the present study is the fact that the diagnosis of echocardiographic LVH was made only by a single observer. In addition, other echocardiographic parameters such as issues of LV diastolic function and tissue Doppler imaging of mitral annulus, pericardial disease, valve calcification, regurgitant mitral and aortic valves, and regional wall motion defect known to confound the assessment of LV geometry and systolic function were not assessed in the present study. Given the inclusion of patients with advanced RKF (stages 4 and 5) whose clinical profile correlate with a high prevalence of $\mathrm{LVH}$, our findings should not be extrapolated to the whole population of patients with RKF. The cross-sectional design of the present study precludes inference for causality. The single measurement of echocardiographic parameters could have overestimated the prevalence of LVH.

\section{Conclusion}

Reduced kidney function in the present hypertensive case series was associated with an increased frequency of left ventricular hypertrophy with mainly concentric geometric pattern and altered systolic function that could enhance their CV risk.

\section{Acknowledgements}

The authors gratefully thank all the staff of the Steering Committee, the Division of Biologic Chemistry and of 
the Division of Cardiology of the University of Kinshasa Hospital for their invaluable contribution to the conduct of the present study.

\section{Conflict of Interest}

None.

\section{Author's Contribution}

-MBC: participated in protocol conception, collected data, participated in data analysis and reviewed the manuscript.

-LFB: conceived the protocol, participated in data analysis and drafted the manuscript.

-MFI: participated in protocol conception, performed data analyses and reviewed the manuscript.

-MJR: reviewed the manuscript.

-KVE: reviewed the manuscript.

-BPM: revised the manuscript.

-MJR: reviewed the manuscript.

\section{References}

[1] Chahal, N.S., Lim, T.K., Jain, P., Chambers, J.C., Kooner, J.S. and Semior, R. (2010) New Insights into the Relationship of Left Ventricular Geometry and Left Ventricular Mass with Cardiac Function: A Population Study of Hypertensive Subjects. European Heart Journal, 31, 588-594. http://dx.doi.org/10.1093/eurheartj/ehp490

[2] Schiffrin, E., Lipman, M.L. and Mann, J.F.E. (2007) Chronic Kidney Disease. Effects on the Cardiovascular System. Circulation, 116, 85-97. http://dx.doi.org/10.1161/CIRCULATIONAHA.106.678342

[3] Shahbaz, A.U., Sun, Y., Bhattacharya, S.K., Ahokas, R.A., Gerling, I.C., McGee, J.E. and Xeber, K.T. (2010) Fibrosis in Hypertensive Heart Disease: Molecular Pathways and Cardioprotective Strategies. Journal of Hypertension, 28, S25-S32. http://dx.doi.org/10.1097/01.hjh.0000388491.35836.d2

[4] Iwashima, Y., Horio, T., Kamide, K., Tokudome, T., Yoshihara, F., Nakamura, S., et al. (2010) Additive Interaction of Metabolic Syndrome and Chronic Kidney Disease on Cardiac Hypertrophy and Risk of Cardiovascular Disease in Hypertension. American Journal of Hypertension, 23, 290-298. http://dx.doi.org/10.1038/ajh.2009.253

[5] Levin, A. (2003) Clinical Epidemiology of Cardiovascular Disease in Chronic Kidney Disease Prior to Dialysis. Seminars in Dialysis, 16, 101-105. http://dx.doi.org/10.1046/j.1525-139X.2003.16025.X

[6] M’Buyamba-Kabangu, J.R., Fagard, R., Staessen, J., Lijnen, P. and Amery, A. (1987) Comparison of Blood Pressure and Prevalence of Hypertension in Rural and Urban Zaire. Bibliotheca Cardiologica, 42, 80-87.

[7] Sumaili, E.K., Nseka, M.N., Lepira, F.B., Krzesinski, J.M., Makulo, J.R., Bukabau, J.B., et al. (2008) Screening for Proteinuria and Chronic Kidney Disease Risk Factors in Kinshasa: A World Kidney Day 2007 Study. Nephron Clinical Practice, 110, c220-c228. http://dx.doi.org/10.1159/000167869

[8] Katchunga, P.B., M’Buyamba-Kayamba, J.R., Masumbuko, B.E., Lemogum, D., Kashongwe, Z.M., Degaute, J.P., et al. (2011) Hypertension in the Adult Congolese Population of Southern Kivu: Results of the VITARAA Study. [French]. La Presse Médicale, 40, e315623.

[9] M’Buyamba-Kabangu, J.R., Biswika, R.T., Thijs, L., Tshimanga, G.M., Ngalula, F.M., Disashi, T., et al. (2009) InHospital Mortality among Black Patients Admitted for Hypertension-Related Disorders in Mbuji Mayi, Congo. American Journal of Hypertension, 22, 643-648. http://dx.doi.org/10.1038/ajh.2009.47

[10] Lepira, F.B., M’Buyamba-Kabangu, J.R., Kayembe, P.K. and Nseka, M.N. (2006) Clinical Correlates of Left Ventricular Hypertrophy in Black Patients with Arterial Hypertension. Cardiovascular Journal of Africa, 17, 7-11.

[11] Bayauli, M.P., Lepira, F.B., Kayembe, P.K. and M’Buyamba-Kabangu, J.R. (2012) Left Ventricular Hypertrophy and Geometry in Type 2 Diabetes Patients with Chronic Kidney Disease: An Echocardiographic Study. Cardiovascular Journal of Africa, 23, 73-77. http://dx.doi.org/10.5830/CVJA-2011-028

[12] Mansia, G., De Backer, G., Dominiczak, A., Cikova, R., Fagard, R., Germano, G., et al. (2007) Guidelines for the Management of Arterial Hypertension: The Task Force for the Management of Arterial Hypertension of the European Society of Hypertension (ESH) and of the European Society of Cardiology (ESC). Blood Press, 16, 135-232. http://dx.doi.org/10.1080/08037050701461084

[13] World Health Organization (2000) The Problem of Overweight and Obesity: Preventing and Managing the Global Epidemic. Report Series 894, WHO, Geneva, 537. 
[14] Dimitrieva, O., de Lusignan, S. and Goldsmith, D. (2013) Association of Anemia in Primary Care Patients with Chronic Kidney Disease: Cross-Sectional Study of Quality Improvement in Chronic Kidney Disease (AICKD) Trial Data. BMC Nephrology, 14, 24. http://dx.doi.org/10.1186/1471-2369-14-24

[15] Expert Committee on the Diagnosis and Classification of Diabetes (2003) Report of Expert Committee on the Diagnosis of and Classification of Diabetes Mellitus. Diabetes Care, 26, S5-S20.

[16] Levey, A.S., Greene, T. and Kusek, J.W. (2000) A Simplified Equation to Predict Glomerular Filtration Rate from Serum Creatinine. Journal of the American Society of Nephrology, 11, Article ID: A0828.

[17] K/DOQI, Kidney Disease Outcome Quality Initiative (2002) Clinical Practical guidelines for Chronic Kidney Disease (CKD). American Journal of Kidney Diseases, 39, S22-S26.

[18] National Heart Lung and Blood Institute (2001) Executive Summary of the Third of National Cholesterol Education Program (NCEP) Expert Panel on Evaluation, and Treatment of High Cholesterol in Adults (Adult Treatment Panel III) (2001). The Journal of the American Medical Association, 285, 2486-2497. http://dx.doi.org/10.1001/jama.285.19.2486

[19] Lang, R.M., Bierig, M., Devereux, R.B., Flachskamp, F.A., Foster, E., Pellikka, P.A., et al. (2006) American Society of Echocardiography's Nomenclature and Standards Committee: Task Force on Chamber Quantification. American College of Cardiology Echocardiography Committee; American Heart Association; European Society of Echocardiography; European Society of Cardiology. Recommendations for Chamber Quantification. European Journal of Echocardiography, 17, 1460-1465.

[20] Adamu, U.G., Kolo, P.M., Katibi, I.A., Opadji, G.O., Omotsho, A.B. and Araoye, A.M. (2009) Relationship between Left Ventricular Diastolic Function and Geometric Patterns in Nigerians with Newly Diagnosed Systemic Hypertension. Cardiovascular Journal of Africa, 20, 173-177.

[21] Devereux, R.B., Alonso, D.R., Lucas, E.M., Gottlieb, E. and Reichek, I. (1986) Echocardiographic Assessment of Left Ventricular Hypertrophy: Comparison to Necropsy Findings. The American Journal of Cardiology, 57, 450-458. http://dx.doi.org/10.1016/0002-9149(86)90771-X

[22] de Simone, G., Devereux, R.B., Daniels, S.R., Koren, M.J., Meyer, R.A. and Laragh, J.H. (1995) Effects of Growth on Variability of Left Ventricular Mass: Assessment of Allometric Signals in Adults and Children and Their Capacities to Predict Cardiovascular Risk. Journal of the American College of Cardiology, 25, 1056-1062. http://dx.doi.org/10.1016/0735-1097(94)00540-7

[23] Lang, R.M., Bierig, M., Devereux, R.B., Flachskampf, F.A., Foster, E., Pellikka, P.A., et al. (2005) Recommendations for Chamber Quantification: A Report from the American Society of Echocardiography's Guidelines and Standards Committee and the Chamber Quantification Writing Group, Developed in Conjunction with the European Association of Echocardiography, a Branch of the European Society of Cardiology. Journal of the American Society of Echocardiography, 18, 1440-1463. http://dx.doi.org/10.1016/j.echo.2005.10.005

[24] Nardi, E., Palermo, A., Mulè, G., Cusimano, P., Cottone, S. and Cerasola, G. (2009) Left Ventricular Hypertrophy and Geometry in Hypertensive Patients with Chronic Kidney Disease. Journal of Hypertension, 27, 633-641. http://dx.doi.org/10.1097/HJH.0b013e3283220ecd

[25] Redón, J., Cea-Calvo, L., Lozano, J.V., Fernández-Pérez, C., Navarro, J., Bonet, A. and González-Esteban, J., ERICHTA 2003 Study Investigators (2006) Kidney Function and Cardiovascular Disease in the Hypertensive Population: The ERIC-HTA Study. Journal of Hypertension, 24, 663-669. http://dx.doi.org/10.1097/01.hjh.0000217848.10831.5f

[26] Ulasi, I.I., Arodiwe, E.B. and Ijoma, C.K. (2006) Left Ventricular Hypertrophy in African Black Patients with Chronic Renal Failure at First Evaluation. Ethnicity \& Disease, 16, 859-864.

[27] Busari, O., Opadijo, G., Olarewaju, T., Omotoso, A. and Jimoh, A. (2010) Electrocardiographic Correlates of Microalbuminuria in Adult Nigerians with Essential Hypertension. Cardiology Journal, 17, 281-287.

[28] Adekunde, A.E., Adeseye, A.I., Adebayo, O.T., Olatayo, A.A., Joseph, O.O. and Ayodele, A.R. (2013) Left Ventricular Mass Formulae and Prevalence Rates of Echocardiographic Left Ventricular Hypertrophy in Nigerians with Essential Hypertension. North American Journal of Medical Sciences, 5, 325-329. http://dx.doi.org/10.4103/1947-2714.112481

[29] Dada, A., Adebiyi, A.A., Aje, A., Oladapo, O.O. and Falase, A.O. (2005) Standard Electrocardiographic Criteria for Left Ventricular Hypertrophy in Nigerian Hypertensives. Ethnicity \& Disease, 15, 578-584.

[30] Dada, A., Adebiyi, A.A., Aje, A., Oladapo, O.O. and Falase, A.O. (2006) Comparison of Araoye's Criteria with Standard Electrocardiographic Criteria for Diagnosis of Left Ventricular Hypertrophy in Nigerian Hypertensives. West African Journal of Medicine, 25, 179-185.

[31] Niakara, A., Ouédraogo, N., Nébié, L.V., Samadoulougou, A.K., Kaboré, N.J. and Ouandaogo, B.J. (2001) Left Ventricular Hypertrophy in Hypertensive African Blacks: Echocardiographic Study of 452 Patients. Annales de Cardiologie et d'Angéiologie, 50, 197-201. (In French) http://dx.doi.org/10.1016/S0003-3928(01)00023-3 
[32] Singh, A.K. and Kari, J.A. (2013) Metabolic Syndrome and Chronic Kidney Disease. Current Opinion in Nephrology and Hypertension, 22, 198-203. http://dx.doi.org/10.1097/MNH.0b013e32835dda78

[33] Chang, J.M., Chen, S.C., Huang, J.C., Su, H.M. and Chen, H.C. (2014) Anemia and Left Ventricular Hypertrophy with Renal Function Decline and Cardiovascular Events in Chronic Kidney Disease. The American Journal of the Medical Sciences, 347, 183-189.

[34] Fraser, S.D., Roderick, P.J., McIntyre, N.J., Harris, S., McIntyre, C.W., Fluck, R.J., et al. (2013) Suboptimal Blood Pressure Control in Chronic Kidney Disease Stage 3: Baseline Data from a Cohort Study in Primary Care. BMC Family Practice, 14, 88. http://dx.doi.org/10.1186/1471-2296-14-88

[35] Cerasola, G., Nardi, E., Palermo, A., Mule, G. and Cottone, S. (2011) Epidemiology and Pathophysiology of Left Ventricular Mass Abnormalities in Chronic Kidney Disease. Journal of Nephrology, 24, 1-10. http://dx.doi.org/10.5301/JN.2010.2030

[36] Aje, A., Adebiyi, A.A., Oladapo, O.O., Dada, A., Ogah, O.S., Ojji, D.B. and Falae, A.O. (2006) Left Ventricular Geometric Patterns in Newly Presenting Nigerian Hypertensives: An Echocardiographic Study. BMC Cardiovascular Disorders, 6, 4. http://dx.doi.org/10.1186/1471-2261-6-4

[37] Adeseye, A., Olayinka, A. and Opadijo, G. (2010) Left Ventricular Hypertrophy, Geometric Patterns and Clinical Correlates among Treated Hypertensive Nigerians. Pan African Medical Journal, 4, 8. http://dx.doi.org/10.4314/pamj.v4i1.53602

[38] Kuch, B., von Scheidt, W., Peter, W., Heier, M., Wichmann, H.E. and Meisinger, C. (2006) Influence of Antihypertensive Therapy and Blood Pressure Control on Left Ventricular Geometry and Function in Subjects with Type 2 Diabetes: The Augsburg Diabetes Family Study. Journal of Human Hypertension, 20, 757-764. http://dx.doi.org/10.1038/sj.jhh.1002062

[39] Gupta, J., Dominic, E.A., Fink, J.C., Ojo, A.O., Barrows, I.R., Reilly, M.P., et al. (2015) Association between Inflammation and Cardiac Geometry in Chronic Kidney Disease: Findings from the CRIC Study. PLoS ONE, 10, e0124772.

[40] Sambi, R.S., Gaur, A.K., Hotchandani, R., Aggarwal, K.K., Kaur, S., Gupta, M., et al. (2011) Patterns of Left Ventricular Hypertrophy in Chronic Kidney Disease: An Echocardiographic Evaluation. Indian Heart Journal, 63, 259-268.

[41] Park, M., Hsu, C.Y., Li, Y., Mishra, R.K., Keane, M., Rosas, S.E., et al. and Chronic Renal Insufficiency Cohort (CRIC) Study Group (2012) Associations between Kidney Function and Subclinical Cardiac Abnormalities in CKD. Journal of the American Society of Nephrology, 23, 1725-1734. http://dx.doi.org/10.1681/ASN.2012020145

[42] Mulè, G., Nardi, E., Guarino, L., Cacciatore, V., Geraci, G., Calcaterra, I., et al. (2015) Plasma Aldosterone and Its Relationship with Left Ventricular Mass in Hypertensive Patients with Early-Stage Chronic Kidney Disease. Hypertension Research, 38, 276-283.

[43] Arodiwe, E.B., Ulasi, I.L., Ijoma, C.K. and Ike, S.O. (2010) Left Ventricular Systolic Function in a Nigerian Pre-Dialysis Patient Population with Chronic Kidney Disease. Nigerian Postgraduate Medical Journal, 17, 301-307.

[44] Grabysa, R. and Wańkowicz, Z. (2013) Echocardiographic Markers of Left Ventricular Dysfunction among Men with Uncontrolled Hypertension and Stage 3 Chronic Kidney Disease. Medical Science Monitor, 19, 838-845. http://dx.doi.org/10.12659/MSM.889586 